\title{
Mechanical, Physical and Tribological Characterization of Nano- Cellulose Fibers Reinforced Bio-Epoxy Composites: An Attempt to Fabricate and Scale the 'Green' Composite
}

\author{
Bamdad Barari $^{1 \dagger}$, Emad Omrani ${ }^{2 \dagger}, *$, Afsaneh Dorri Moghadam ${ }^{2}$, Pradeep L. Menezes ${ }^{3}$, Krishna \\ M. Pillai ${ }^{1}$, Pradeep K. Rohatgi ${ }^{2}$ \\ ${ }^{1}$ Department of Mechanical Engineering, College of Engineering \& Applied Science, University of \\ Wisconsin, Milwaukee, WI 53211, USA \\ ${ }^{2}$ Tribology Lab and Center for Advanced Materials Manufacturing, Department of Materials Science and \\ Engineering, College of Engineering \& Applied Science, University of Wisconsin, Milwaukee, WI 53211, USA \\ ${ }^{3}$ Department of Mechanical Engineering, University of Nevada, Reno, Nevada 89557, USA
}

\begin{abstract}
The development of bio-based composites is essential in order to protect the environment while enhancing energy efficiencies. In the present investigation, the plant-derived cellulose nano-fibers (CNF)/ bio-based epoxy composites were manufactured using the Liquid Composite Molding (LCM) process. More specifically, the CNFs with and without chemical modification were utilized in the composites. The curing kinetics of the prepared composites was studied using both the isothermal and dynamic Differential Scanning Calorimetry (DSC) methods. The microstructure as well as the mechanical and tribological properties were investigated on the cured composites in order to understand the structure-property correlations of the composites. The results indicated that the manufactured composites showed improved mechanical and tribological properties when compared to the pure epoxy samples. Furthermore, the chemically modified CNF reinforced composites outperformed the untreated composites. The surface modification of the fibers improved the curing of the resin by reducing the activation energy, and led to an improvement in the mechanical properties. The CNF/ bio-based epoxy composites form

\footnotetext{
$\dagger$ These authors contributed equally to this work.

* Corresponding author: Emad Omrani, e-mail address: eomrani@uwm.edu, emad.omrani@gmail.com
} 
uniform tribo-layer during sliding which minimizes the direct contact between surfaces, thus reducing both the friction and wear of the composites.

Keywords: Resin Transfer Molding; Nanocomposites; Polymer Matrix Composites; NanoCellulose Fiber; Tribology; Friction and Wear

\section{Introduction}

In recent years, the natural fibers have been considered as an alternative to the synthetic fibers for reinforcement in polymeric composites because of the economic and environmental advantages. The increasing world awareness of the environmental issues along with an intensification of the global energy crisis has generated an interest in utilizing natural fibers in industries and academics (Brosius, 2006; Omrani, Menezes \& Rohatgi, 2015). Other advantages of natural fibers compared to synthetic fibers are - abundance, non-toxicity, non-corrosiveness, bio-degradability, lower cost, and low energy production costs - which makes them potential candidates in the secondary structural applications in automotive industry, including door panel and package trays (Cheung, Ho, Lau, Cardona \& Hui, 2009; Wambua, Ivens \& Verpoest, 2003). In recent years, many investigators have conducted research on different types of natural fibers as reinforcement for various polymer matrices. The effects of using plant-derived fibers, such as hemp, jute, kenaf, bamboo and treated palm-tree fiber on mechanical strength, stiffness, thermal and tribological properties of the produced composites have been investigated. It was found that the natural fibers possess poor mechanical properties as compared to the synthetic fibers, such as the carbon and glass fibers. As a result, the natural-fiber composites suffer from low mechanical, thermal and tribological properties. These poor properties are essentially due to the inherent polarity and their incompatibility with non-polar polymers. (Alawar, Hamed \& Al-Kaabi, 2009; Chand \& Dwivedi, 2007; Chin \& Yousif, 2009; Hepworth, Vincent, Jeronimidis \& Bruce, 2000; Qamhia, Shams \& El-Hajjar, 2015; Saha, Manna, Chowdhury, Sen, Roy \& Adhikari, 2010; Virk, Hall \& Summerscales, 2010).

Many studies have been conducted in recent years to investigate the mechanical properties of the natural-fiber reinforced composites. Several factors on the influence of natural fibers on mechanical performance of the composites have been studied. These factors include interfacial adhesion, orientation, strength and physical properties of the fibers. Alwar et al. 
(Alawar, Hamed \& Al-Kaabi, 2009) investigated the effects of chemical treatment on surface morphology for date palm tree fibers. Based on their study, fibers treated with $1 \%$ Sodium Hydroxide $(\mathrm{NaOH})$ solution showed the optimum mechanical properties of the composites. However, hydrochloric acid $(\mathrm{HCl})$ treatment resulted in deterioration in mechanical properties of the composites. Saha et al. (Saha, Manna, Chowdhury, Sen, Roy \& Adhikari, 2010) studied the influence of alkali treatment on tensile strength of jute fiber reinforced composites under ambient temperature. Their investigation indicated that dipping fibers in alkali solution lead to an increase in the tensile strength of the composites. Furthermore, several studies have showed a positive effect of adding kenaf, hemp and cotton fibers to alkali solution to enhance the tensile strength of Polypropylene composites (Kim, Moon, Kim \& Ha, 2008; Venkateshwaran, Elayaperumal \&

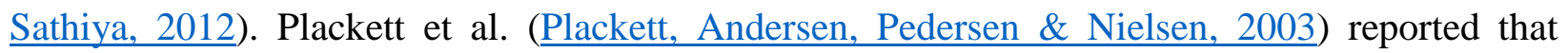
adding jute fibers to polylactic acid (PLA) enhanced the tensile strength of the composites up to 75\%. Barari et al. (Barari et al., 2015) studied the effects of silane treatment on bonding between cellulose nano-fibers and epoxy, and detected its overall effect on mechanical properties of the final composite. This study also includes other aspects, such as moisture absorption, impurities and volume fraction which play an important role on the properties of manufactured composite. Masoodi et al. (Masoodi, El-Hajjar, Pillai \& Sabo, 2012) studied the crack behavior of cellulose nano-fiber composites.

Determining an optimum value of fiber volume fraction for the best strength is another significant topic in field of composites. Hence, the effects of fiber volume fraction on the strength-related properties have been investigated by several researchers. These studies have shown that the natural fibers tend to weaken the bonding with the matrix at high fiber volume fraction (> 50\%) (Haque, Hasan, Islam \& Ali, 2009; Ku, Wang, Pattarachaiyakoop \& Trada, 2011; Shibata, Cao \& Fukumoto, 2005; Venkateshwaran, Elayaperumal \& Sathiya, 2012). Further, some studies have reported on the influence of fiber-matrix interface on mechanical properties of the composites as it is a key parameter in transferring stress from the matrix to the fibers (Shalwan \& Yousif, 2013).

The tribological properties of polymeric composites reinforced by natural fibers have been a topic of interest in the field of green tribology in recent years (Yousif, Lau \& McWilliam, 2010). As most of the engineering parts are exposed to tribological effects, such as adhesion and abrasion, understanding the tribological behavior of the natural fiber reinforced composite is as 
essential as understanding the mechanical performance of the composites. Some research has been done on investigating the tribological properties of natural-fiber reinforced composites, such as wear and frictional behavior of polymer composites reinforced with kenaf (Chin \& Yousif, 2009), oil palm (Yousif \& El-Tayeb, 2008), and bamboo (Nirmal, Hashim \& Low, 2012), jute (Chand \& Dwivedi, 2006). These studies have shown a diverse tribological behavior based on the type of reinforcement used in the composites. However, no investigations have been conducted till date on the effects of natural nano-fibers on the tribological behavior of nanocomposites.

Cellulose nano-fiber (CNFs), a new type of natural nanoscale fiber, made purely from cellulose molecules, have shown a remarkable mechanical properties compared to other natural fibers as well as glass and carbon fibers (Henriksson \& Berglund, 2007; Henriksson, Berglund, Isaksson, Lindström \& Nishino, 2008; Lee, Chun, Kang \& Park, 2009). However, a drawback of using nano-fibers in the last few decades was due to a bottleneck in their manufacture from cellulose molecules due to the extremely high energy needed till now to separate cellulose molecules from pulp. Recent improvement in the technologies and techniques for making highly porous cellulosic nano-fiber based aerogels reduced the production costs to reasonable values. This led to an increased interest on investigating many aspects of the composites using CNFs as reinforcement in natural composites in the last few years (Jonoobi, Harun, Mathew \& Oksman, 2010; Saito et al., 2009; Teixeira, Pasquini, Curvelo, Corradini, Belgacem \& Dufresne, 2009). Aerogels are light-weight and highly porous materials that are prepared by removing liquid solvent from a gel, as a result of which a solid skeleton is created with large number of pores inside the solid phase. Formation of aerogels is usually accomplished through common processes including freeze-drying and vacuum-drying. CNF aerogels owing to low density (0.004-0.5 $\mathrm{g} / \mathrm{cm}^{3}$ ) and very high porosity (above $90 \%$ ) can be employed as a porous reinforcement that can be easily infiltrated with resin under pressure to manufacture composites (Balali, Nouri \& Pakdamanian, 2013; Hüsing \& Schubert, 1998; Innerlohinger, Weber \& Kraft, 2006; Tan, Fung, Newman \& Vu, 2001).

In the present investigation, the silylated and non-silylated CNF aerogels were used as reinforcements and a bio-based epoxy as the matrix materials for making CNF/epoxy nanocomposite using an improvised Liquid Composite Molding (LCM) process. The curing of silylated and non-silylated CNF composites was investigated through isothermal and non- 
isothermal Differential Scanning Calorimetry (DSC) tests. Mechanical properties, such as tensile strength and modulus of elasticity of these composites were investigated using the traditional tensile-testing process. The effect of silane treatment on the mechanical properties of nanocomposites was also studied by comparing the strengths of the treated and non-treated samples. Tribological investigations, such as the friction coefficient and wear behavior of the CNF composites were studied under various sliding speeds and loads. The worn surfaces were analyzed using Scanning Electron Microscopy (SEM) and optical profilometer.

\section{Manufacturing process}

\subsection{Cellulose nano-fiber (CNF) aerogels}

The CNF aerogels used in the present investigation were derived from commerciallysupplied Eucalyptus Kraft pulp which were used as raw material and were processed using acid hydrolysis, TEMPO (tetramethylpiperidine-1-oxyl) oxidation, and mechanical stress. The CNF aerogel preparing process was initiated with washing, pre-treating and soaking of the Eucalyptus Kraft pulp with acid and water, and then filtering the pre-treated fibers. After filtration, the products were carboxylate with the reactants according to Saito's methodology (Saito et al., 2009). The centrifugation process was used to facilitate the separation of coarse and fine fractions. Then, a nano-fiber suspension was prepared using microfluidizer. In the final step, the CNF preforms were prepared from the nano-fiber suspension using the freeze-drying process. The process could be manipulated to create either randomly oriented pore or highly aligned unidirectional pores in the preforms (Barari \& Pillai, 2015). This micro-scale structure would allow the preform to be used as high-porous preforms for making CNF composites. In order to increase the wettability and infusion properties of such preforms, the CNF preforms were placed in a glass vacuum desiccator above $1 \mathrm{~mL}$ of trimethoxy-octadecyl silane (for each preform) and stored in a vacuum oven at 1 inch $\mathrm{Hg}$ and $120^{\circ} \mathrm{C}$ for $18 \mathrm{hrs}$. 


\subsection{Manufacturing of CNF composites using an improvised Liquid Composite Molding (LCM) process}

The CNF composites are manufactured using an improvised LCM process where the CNF aerogels are used as preform and the bio-based epoxy as the matrix. The improvised LCM process was essentially based on a conventional vacuum-assisted resin transfer molding (VARTM) process where a vacuum up to $100 \mathrm{kPa}$ was applied to pull the resin through the preform inside a mold (Barari et al., 2015; Barari \& Pillai, 2014). The experimental setup consists of a vacuum pump, a resin trap and a 'micro' LCM mold. The micro LCM mold was made from aluminum and sealed by polycarbonate cap at the top. Two aluminum portable inserts, used to create tensile and flexural specimens, were placed inside the base slab. The transparent Lexan ${ }^{\circledR}$ cap was employed to air seal the mold and also used as a window to track the resin movement inside the mold.

The bio-based resin used in the present experimental processes was Super-Sap Entropy ${ }^{\circledR}$ (Tjong \& Tam, 2006), which is derived from industrial waste products, such as wood pulp, and has an overall bio-content of around 50\%. This resin was designed to be cured at room temperatures, and thus has an enhanced processability during the VARTM process.

In the manufacturing process, the cellulose preform was placed inside the mold cavity while the Lexan ${ }^{\circledR}$ cap was fastened on the top. The inlet vent was connected to a beaker full of curing resin and the outlet vent was connected to the resin trap in order to prevent any leakage of the resin to the inside of the vacuum pump. During the process, the resin was made to pass through the porous and permeable preform along the mold cavity and then was made to exit through the outlet vent to the resin trap. The resin was set and cured for 24 hours and then the specimens were removed from the mold. Thereafter, the specimens were placed inside an oven that was set at $130{ }^{\circ} \mathrm{C}$ for 20 minutes. The freeze-dried CNF preform, being an aerogel, typically had very low solid-phase volume fractions. As a result, the manufactured CNF composite had very low fiber volume fractions (FVF) where the samples typically had FVF from 0.9 to $1.4 \%$. For tribological studies, cylindrical samples with hemispherical-shaped tip were prepared from the specimen by machining. 


\section{Characterization and testing}

\subsection{Differential scanning calorimetry tests}

Differential scanning calorimetry (DSC) tests were performed on the prepared samples using a Q1000 DSC developed by TA Instruments. In these experiments, $25 \mathrm{mg}$ of uncured bioepoxy fiber composite was placed in T-Zero aluminum pans under $50 \mathrm{~mL} / \mathrm{min}$ of nitrogen purge gas. To study the curing process of the composites, both the isothermal and non-isothermal tests were performed. In addition, the glass transition temperature of the cured composites was measured by performing additional heating and cooling cycles. Three individual tests were carried out to ensure reliability of measurements. For non-isothermal tests, a heat-cool-heat cycle for temperature range between -60 to $+250{ }^{\circ} \mathrm{C}$ at a heating rate of $10{ }^{\circ} \mathrm{C} / \mathrm{min}$ was used for the uncured sample. The onset temperature for curing $\left(T_{o n}\right)$, the melting temperature $\left(T_{m}\right)$, and the glass transition temperature $\left(\mathrm{T}_{\mathrm{g}}\right)$ were obtained using the Universal Analysis 2000 software that is attached to the data acquisition electronics of the DSC.

For isothermal studies, three different temperatures were selected based on the curing peak position of the non-isothermal tests. The temperatures were selected in such a way that it should range between a temperature below the onset of the reaction, a temperature midway to the peak maximum, and a temperature well above the peak position. Prior to performing isothermal experiments, the chamber was heated to the desired isothermal temperature using an initial temperature program segment. The chamber was rapidly opened for loading the sample and was then immediately closed. When the measured temperature was within $4^{\circ} \mathrm{C}$ of the desired isothermal temperature, the data acquisition was initiated.

\subsection{Mechanical characterization}

The tension coupons prepared from CNF/bio-epoxy composite were tested using a tensile testing machine. The loading force was set using a displacement controlled device at the rate of $1.3 \mathrm{~mm} / \mathrm{min}(0.05 \mathrm{in} / \mathrm{min})$. The crosshead displacement and loading force were recorded during the experiments. The load was applied through an electro-mechanical test system with a $97 \mathrm{kN}$ capacity. A sample length of $89 \mathrm{~mm}$ (3.5 in) was considered as the gauge length in the tensile testing process. All the specimens were tested by the same operator using the same testing machine in order to avoid any errors that might occur due to variations in the testing conditions. 
The CNF composites with various fiber volume fractions were tested and the strength and module of elasticity values were compared. In addition, the effects of silane treatment on mechanical properties of CNF composites were investigated in order to compare the tensile strength and elastic modulus values.

\subsection{Tribological characterization}

The pin-on-disk tests (ASTM G99) under dry condition were performed to investigate the tribological behavior of the composites at ambient conditions. In the test, a stationary pin was made to slide against a rotating disk. From the fabricated composite specimens, cylindrical samples (10 $\mathrm{mm}$ in length, $3 \mathrm{~mm}$ in diameter, and with rounded contact surface) were prepared by machining. The disks were made of hardened 440C stainless steel with hardness of $230 \mathrm{HBN}$ and initial surface roughness $\left(R_{\mathrm{a}}\right)$ of $0.3 \pm 0.05 \mu \mathrm{m}$. The disk dimensions were $55 \mathrm{~mm}$ in dimeter and $10 \mathrm{~mm}$ in thickness. In addition, the tribological properties were studied by varying the tribological testing parameters, such as normal loads $(4 \mathrm{~N}, 7 \mathrm{~N}$ and $10 \mathrm{~N})$ and sliding speeds (low $(0.15 \mathrm{~m} / \mathrm{s})$, medium $(0.25 \mathrm{~m} / \mathrm{s})$ and high $(0.35 \mathrm{~m} / \mathrm{s}))$. For each test, the sliding distance was fixed to $1 \mathrm{~km}$ in order to consider the steady-state friction values. The COF (coefficient of friction) value presented for each test was the average of the friction values. In addition, the linear wearloss was acquired through a linear variable differential transducer (LVDT) with an encoder, which recorded the vertical displacement of the pin. After the tests, the worn surfaces were analyzed using SEM. The linear wear loss of each pin was converted into a volumetric wear loss using Eq. (1) derived from the geometry of a spherical cap.

$$
V=\frac{\pi h^{2}}{3}(3 r-h)
$$

In Eq. (1), $h$ is the linear displacement ( $\mathrm{mm})$ in the vertical (longitudinal) axis for the pin, $r$ is the pin radius (mm), which is assumed to be constant throughout the test, and $V$ is the volumetric wear loss $\left(\mathrm{mm}^{3}\right)$. For a given set of testing conditions, at least three repetitive tests were performed and the results of the average of three tests were presented.

\section{Results and discussion}

\subsection{DSC characterization}

\subsubsection{Dynamic DSC characterization}


The effects of coupling agents on curing of the fiber/bio-epoxy composites were systematically studied using dynamic DSC methods by analyzing temperature ramp curve for pure bio-epoxy, cellulose nano-fibers (CNFs)/bio-based epoxy composites, and chemically modified silylated cellulose nano-fibers (CNFs)/bio-based epoxy composite. All thermographs showed an exothermic peak ranging from $40^{\circ} \mathrm{C}$ to $150{ }^{\circ} \mathrm{C}$. The onset temperature for curing $\left(\mathrm{T}_{\mathrm{on}}\right)$, the melting temperature $\left(\mathrm{T}_{\mathrm{m}}\right)$, and the glass transition temperature $\left(\mathrm{T}_{\mathrm{g}}\right)$ are presented in Table 1.

Table 1 Characteristic temperatures of pure bio-epoxy and composites, obtained using the temperature ramp analysis

\begin{tabular}{|c|c|c|c|}
\hline & $\mathbf{T}_{\mathbf{m}}$ & $\mathbf{T}_{\mathbf{o n}}$ & $\mathbf{T}_{\mathbf{g}}$ \\
\hline Pure bio-epoxy & 128 & 87 & 73 \\
\hline Silylated CNF/ Bio-epoxy composite & 125 & 79 & 55 \\
\hline Non- silylated CNF/ Bio-epoxy composite & 124 & 87 & 57 \\
\hline
\end{tabular}

Compared to the pure bio-epoxy sample, the onset temperature for curing for the unmodified CNF remained unchanged, however, the onset temperature was decreased for the fiber modified CNF. The peak temperature $\left(\mathrm{T}_{\mathrm{m}}\right)$ remained almost unaffected for both the surface modified and unmodified fibers. These variations can be explained by the catalytic effects of the fibers during the curing process of bio-epoxy. At the initial stages of curing, the decrease in the onset temperature can considered as an evidence of acceleration in curing in the early stage of the curing process. Siloxane functional groups $\left(-\mathrm{SiO}_{2}\right)$ on the surface of the CNF react with the bio-epoxy ring and this is expected to modify the curing behavior. The slight acceleration in curing of the unmodified fibers in the early stage of the reaction is a result of decrease in the activation energy with the addition of the CNF. However, fibers hinder the reaction after that step and this can explain the unchanged peak temperature of the pure and filled bio-epoxy. The lack of bio-epoxy-chain mobility in the presence of fibers retards the polymer chain extension process.

The thermo-mechanical stability of polymers is closely related to their glass transition temperature, which itself would change with the molecular structure, the functionality of the system, the degree of the cure, the type of the curing, etc. The glass transition temperature of a system is expected to increase with a decrease in the chain mobility. The glass transition temperatures of the CNF reinforced composites are lower than those of the unfilled bio-epoxy. 
This is because of the restricted mobility of the polymer chains in the vicinity of the fibers. In addition, the fibers are also inducing a stiffening effect that promotes $\mathrm{T}_{\mathrm{g}}$.

\subsubsection{Isothermal DSC}

The isothermal DSC characterization of the silylated and non-silylated CNF composites for three different temperatures was conducted. The variation of heat flow with time is shown in Figure 1a. As displayed in the isothermal results (Figure 1b), both silylated and non-silylated samples reached to full conversion at $130^{\circ} \mathrm{C}$. At the higher temperatures, the silylated samples reached the maximum conversion in a shorter time compared to the non-silylated samples while this tendency was quite the opposite at lower temperatures. The silylated samples showed higher conversion by increasing the isothermal temperature. However, this effect was more pronounced when the temperature was high enough. By increasing the temperature in the isothermal DSC process, the time required to achieve full conversion was decreased. This implies that the fiber induced modification was enhanced only during the initial stages of curing by decreasing the activation energy. In addition, the kinetic parameters were calculated using the normalized heat flow vs time curves as shown in Figure $1 \mathrm{~b}$ where the normalized curves were used to derive an equation for curing percentage as a function of time. The equation model is derived using the Sigmoidal Dose-Response equation as

$$
\alpha(t)=A_{1}+\frac{A_{2}-A_{1}}{1+10^{\left[\left(\log _{0}-t\right) p\right]}}
$$

where $A_{1}$ is the $y$-minimum plateau, $A_{2}$ is the $y$-maximum plateau, Log $t_{0}$ is the $t$ value when $\alpha(t)$ is halfway between the bottom and the top, and $\mathrm{p}$ is the hillslope or the steepness of the curve. All the above mentioned parameters for the conversion equation are presented in Table 2.

Table 2 Parameters of eq. 1, conversion equation as a function of time parameters.

\begin{tabular}{|c|c|c|c|c|c|}
\hline \multirow{2}{*}{ Temperature } & Sample & $\mathbf{A}_{\mathbf{1}}$ & $\mathbf{A}_{\mathbf{2}}$ & $\mathbf{L o g t}_{\mathbf{0}}$ & $\mathbf{p}$ \\
\hline \multirow{2}{*}{80} & Silylated & -13.9 & 1 & -14.48 & 0.07 \\
\cline { 2 - 6 } & Non-silylated & -20.33 & 1 & -13.33 & 0.1 \\
\hline \multirow{2}{*}{100} & Silylated & -2635.72 & 0.98 & -22.56 & 0.15 \\
\cline { 2 - 6 } & Non-silylated & -875.02 & 0.99 & -11.25 & 0.25 \\
\hline
\end{tabular}




\begin{tabular}{|l|c|c|c|c|c|}
\hline \multirow{3}{*}{130} & Silylated & -0.73 & 1 & 0.15 & 1.27 \\
\cline { 2 - 6 } & Non-silylated & -4.5 & 1 & -0.73 & 0.82 \\
\hline
\end{tabular}
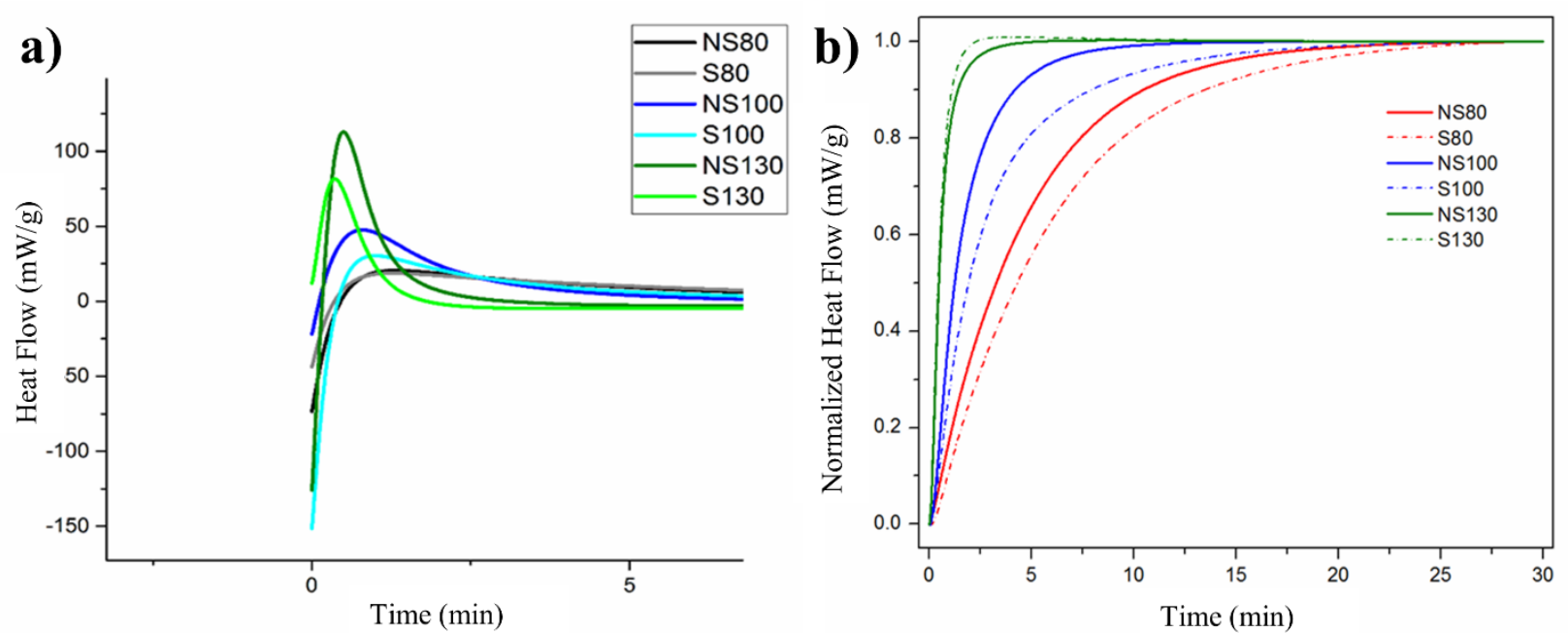

Figure 1 a) Variation of heat flow with time for the silylated " $S$ " and non-silylated "NS" CNF samples at 80, 100 and $130{ }^{\circ} \mathrm{C}$ and $\mathrm{b}$ ) Normalized Heat flow with time diagram for silylated and non-silylated CNF samples at 80, 100 and $130^{\circ} \mathrm{C}$.

\subsection{Mechanical properties}

The stress-strain diagram measured by tensile test for the silylated and non-silylated CNF composite samples is shown in Figure 2(a). As shown in the stress-strain diagram, the silylated CNF shows superior ultimate tensile strength and higher modules of elasticity when compared to the non-silylated samples. The stress-strain relations for the silylated and non-silylated CNF composites are almost linear at the beginning and the linearity declines with increasing strain. In general, the CNF reinforced specimens showed a nonlinear stress-strain response that indicates lowering of the brittleness of the bio-epoxy composites in the presence of CNF preform. This could be explained by the observed formation of dry spots inside the composite at the CNF/bioepoxy interface due to incomplete infusion of CNF preforms. 

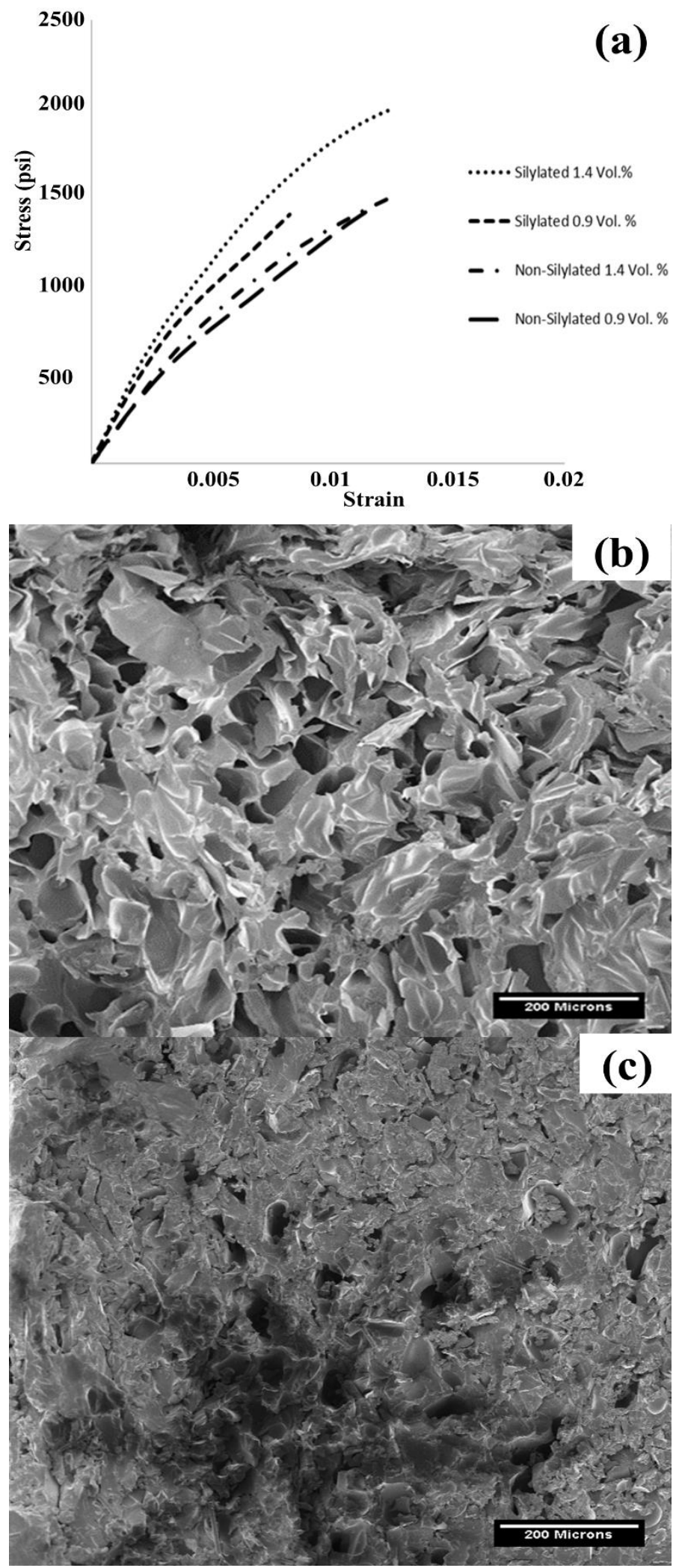

Figure 2 a) Experimentally measured stress-strain curves for the CNF/bio-epoxy composites and SEM micrographs of b) non-silylated CNF composite and c) silylated CNF composite. 
The SEM micrographs of the fractured surface of the CNF composites are shown in Figure 2 (b) and (c). The silylated sample shows much less bubbles or voids compared to the non-silylated sample; the latter displays more numerous round voids. This difference can be attributed to the better wettability of the CNF preform by the resin in presence of the silane agent. The silane agent also improves the mechanical entanglement between the CNF reinforcement and bio-epoxy matrix due to better bonding between them during the curing process. Both these effects (i.e., reduced void formation and improved entanglement) work together to create a better CNF composite.

\subsection{Tribological Properties}

In the pin-on-disk experiments, the continuous rotating steel counterface slide against the stationary surface of the sample (composite material). This rubbing action results in creation of continuous grooves on the specimen surface, and subsequently the material detach from the specimen surface due to continuous rubbing, and finally leading to material removal from the

specimen surface. As the mechanical properties of the composites reinforced by silylated CNF are superior to those of the composites reinforced by non-silylated CNFs and it is well know that the mechanical properties strongly influence tribological properties (Menezes, Nosonovsky, Kailas \& Lovell, 2013), hence, the tribological properties of silylated CNFs/bio-epoxy composites were investigated in this study. Experiments were performed to determine the influence of the presence of nano-cellulose in the bio-epoxy matrix on the tribological properties, such as coefficient of friction (COF) and wear volume loss of the composites.

\subsubsection{Effect of volume fraction}

Figure 3 (a), (b) and (c) shows the effect of the presence of nano-cellulose in the bioepoxy matrix on COF at different normal loads and sliding speeds. In the figures, the connecting data points pertain to the average values of the three tests. Figure 3(a) shows the variation of the $\mathrm{COF}$ with volume fraction of nano-cellulose in the bio-epoxy matrix at $4 \mathrm{~N}, 7 \mathrm{~N}$ and $10 \mathrm{~N}$ for a sliding speed of $0.15 \mathrm{~m} / \mathrm{s}$. It can be seen that the COF decreases with increasing volume fraction of nano-cellulose in the bio-epoxy for all the three normal loads during the low sliding speed of $0.15 \mathrm{~m} / \mathrm{s}$. Interestingly, the reduction in $\mathrm{COF}$ is significant for larger normal loads. It is also obvious that the reduction in friction is substantial when the volume fraction of nano-cellulose is 
increased from $0 \%$ to $0.9 \%$ than $0.9 \%$ to $1.4 \%$. It can be inferred from Figure 3 (a) that the neat bio-epoxy showed better tribological performance at lower normal loads and the $1.4 \%$ composite showed better tribological performance at higher normal loads due to the presence of nanocellulose on contact surfaces.

Figure 3(b) shows the variation of $\mathrm{COF}$ with volume fraction of nano-cellulose in the bioepoxy matrix at $4 \mathrm{~N}, 7 \mathrm{~N}$ and $10 \mathrm{~N}$ when the tests were performed for a constant sliding speed of $0.25 \mathrm{~m} / \mathrm{s}$. Akin to $0.15 \mathrm{~m} / \mathrm{s}$, the coefficient of friction decreases when $0.9 \%$ volume fraction of nano-cellulose was added to the bio-epoxy for all the three normal loads. However, the COF increases for $4 \mathrm{~N}$ and $7 \mathrm{~N}$ when $1.4 \%$ nano cellulose added to the bio-epoxy matrix, although, they have lower COF than the neat bio-epoxy. Interestingly, for $10 \mathrm{~N}$, the COF continuously decreases although the reduction in COF is less substantial. Incidentally, the $10 \mathrm{~N}$ load led to the lowest COF. Here too, the neat bio-epoxy showed better tribological performance at lower normal loads and the $1.4 \%$ composite showed superior tribological performance at higher normal loads.

Figure 3(c) shows the variation of $\mathrm{COF}$ with volume fraction of nano-cellulose in the bioepoxy matrix at $4 \mathrm{~N}, 7 \mathrm{~N}$ and $10 \mathrm{~N}$ for a constant sliding speed of $0.35 \mathrm{~m} / \mathrm{s}$. At this high sliding speed, the variation of $\mathrm{COF}$ with volume fraction of nano-cellulose showed completely different trends. At $4 \mathrm{~N}$ normal load, the variations in the $\mathrm{COF}$ is increased when $0.9 \%$ volume fraction of nano-cellulose is added to the bio-epoxy matrix and then the COF is slightly decreased when $1.4 \%$ nano-cellulose is added to the bio-epoxy matrix. The COF was found to be lowest for the neat bio-epoxy when compared to the nano composites. For $7 \mathrm{~N}$ normal load, the $\mathrm{COF}$ does not change much with nano-cellulose volume fraction. Interestingly, at the highest normal load of $10 \mathrm{~N}$, the COF decrease with the increasing volume fraction of nano-cellulose as observed for the $0.15 \mathrm{~m} / \mathrm{s}$ and $0.25 \mathrm{~m} / \mathrm{s}$ sliding speeds. From the above results, it can be inferred that the neat bioepoxy has poor tribological properties and suitable only at low loads and low sliding speeds applications. However, for severe tribological conditions, the higher volume fraction of the nano-cellulose would be preferred in the CNF composites. 

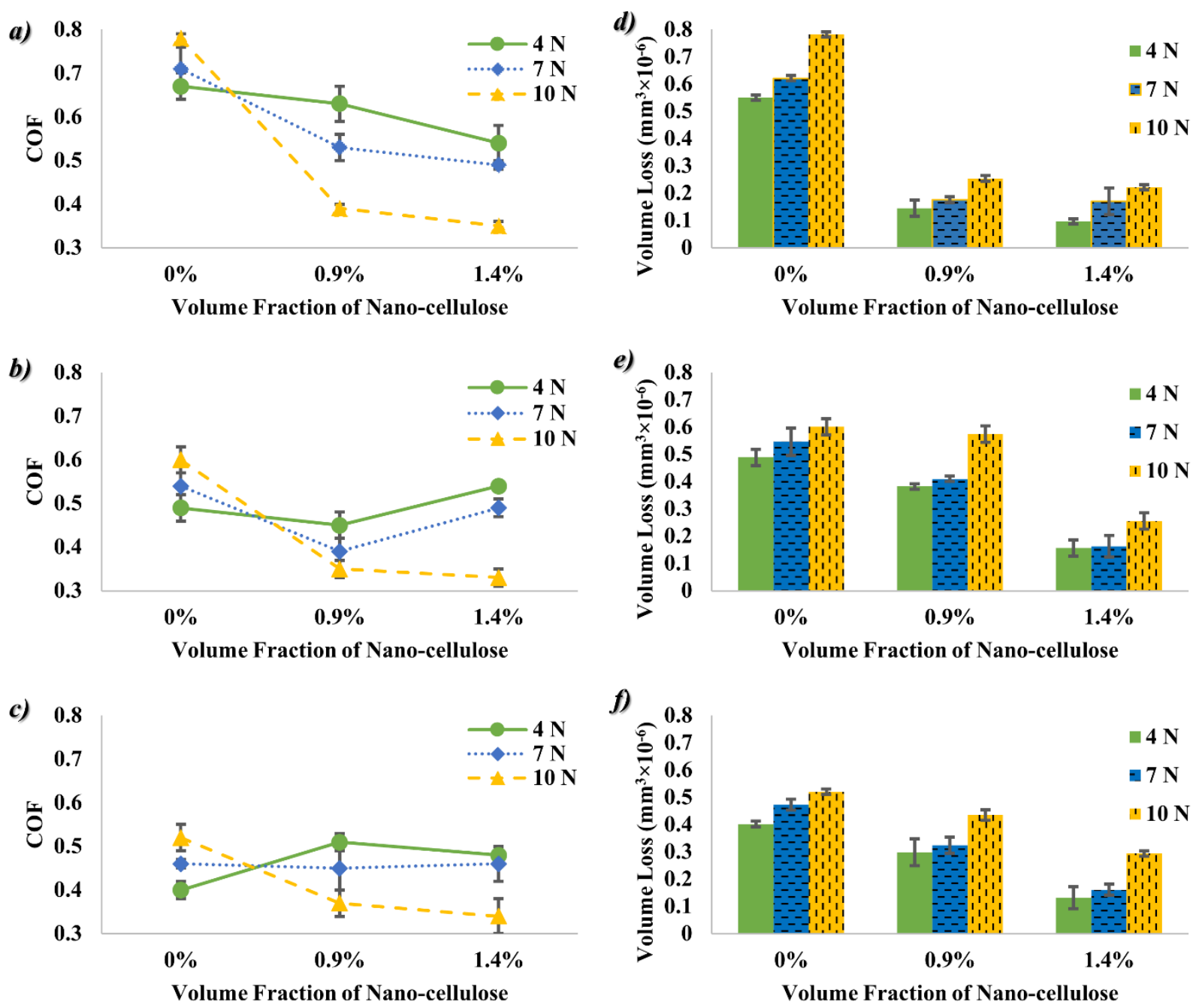

Figure 3 Effect of nano-cellulose content in bio-epoxy on coefficient of friction at different normal loads for a) $0.15 \mathrm{~m} / \mathrm{s}, \mathrm{b}) 0.25 \mathrm{~m} / \mathrm{s}$, and c) $0.35 \mathrm{~m} / \mathrm{s}$ sliding speeds and effect of nano-cellulose in bio-epoxy on wear volume at different normal loads for d) $0.15 \mathrm{~m} / \mathrm{s}$, e) $0.25 \mathrm{~m} / \mathrm{s}$, and f) $0.35 \mathrm{~m} / \mathrm{s}$ sliding speeds..

Figure 3(d), (e) and (f) show the variation of wear rate (volume loss) with volume fraction of nano-cellulose in the bio-epoxy matrix for various normal loads (4N, $7 \mathrm{~N}$ and $10 \mathrm{~N})$ at sliding speeds of $0.15 \mathrm{~m} / \mathrm{s}, 0.25 \mathrm{~m} / \mathrm{s}$ and $0.35 \mathrm{~m} / \mathrm{s}$, respectively. It can be seen that for a given volume fraction, the wear rate increases with increasing normal load. The wear rate decreases with the increasing volume fraction of the cellulose in the bio-epoxy matrix. Furthermore, the wear rate decreases with the increasing sliding speed. The volume loss in nano-cellulose/bioepoxy composites is significantly less than that of the neat bio-epoxy. This is because the incorporation of nano-cellulose in the bio-epoxy matrix effectively improves the mechanical and tribological properties of bio-epoxy due to the enhancement in strength properties as shown in 
Figure 2(a) and the ability of nano-cellulose fibers to resist the bending force as reported in the literature (Alamri \& Low, 2012b). Although, the hardness of the material has long been regarded as a primary material property that defines the wear resistance, there are strong evidences to suggest that the elastic modulus can also have an important influence on the wear behavior (Leyland \& Matthews, 2000). Subsequently, the bio-epoxy matrix reinforced by $1.4 \%$ CNFs have better wear properties due to higher elastic modulus as shown in Figure 2(a). In addition, the cellulose fibers play a significant role in enhancing fracture toughness of polymer matrices through several energy absorbing mechanisms, such as fiber pullout, fiber fracture and fiberbridging (Low, Somers, Kho, Davies \& Latella, 2009). These mechanical factors have significant effect on the tribological properties of nano-cellulose/bio-epoxy composites. Besides, the addition of nano-cellulose into bio-epoxy results in an improvement in the COF and reduction in the volume loss of nanocomposites. In general, as demonstrated in Figure 3(d), (e) and (f), superior improvement in wear rate occurred at the highest volume fraction of CNFs due to the increase in stress transferred to the fiber and the ability of cellulose fibers to resist the bending forces (Alamri \& Low, 2012a) and can carry the major load and support the bio-epoxy matrix. Table 3 shows the amount of improvements in COF and wear rate of the CNFs reinforced composites.

\begin{tabular}{|c|c|c|c|c|c|}
\hline \multirow[b]{3}{*}{$\begin{array}{l}\text { Sliding } \\
\text { Speed }\end{array}$} & \multirow[b]{3}{*}{ Load } & \multicolumn{4}{|c|}{ CNFs Volume Fraction } \\
\hline & & $0.9 \%$ & $1.4 \%$ & $0.9 \%$ & $1.4 \%$ \\
\hline & & \multicolumn{2}{|c|}{$\begin{array}{c}\text { COF } \\
\text { Improvement }\end{array}$} & \multicolumn{2}{|c|}{$\begin{array}{c}\text { Volume Loss } \\
\text { Improvement }\end{array}$} \\
\hline \multirow{3}{*}{$0.15 \mathrm{~m} / \mathrm{s}$} & $4 N$ & $6.0 \%$ & $19.4 \%$ & $73.8 \%$ & $82.5 \%$ \\
\hline & $7 \mathrm{~N}$ & $25.4 \%$ & $31.0 \%$ & $71.7 \%$ & $72.6 \%$ \\
\hline & $10 \mathrm{~N}$ & $50.0 \%$ & $55.1 \%$ & $67.5 \%$ & $71.6 \%$ \\
\hline \multirow{3}{*}{$0.25 \mathrm{~m} / \mathrm{s}$} & $4 N$ & $8.2 \%$ & $-10.2 \%$ & $21.9 \%$ & $67.9 \%$ \\
\hline & $7 \mathrm{~N}$ & $27.8 \%$ & $9.3 \%$ & $25.0 \%$ & $70.2 \%$ \\
\hline & $10 \mathrm{~N}$ & $41.7 \%$ & $45.0 \%$ & $4.5 \%$ & $57.4 \%$ \\
\hline \multirow{3}{*}{$0.35 \mathrm{~m} / \mathrm{s}$} & $4 N$ & $-27.5 \%$ & $-20.0 \%$ & $25.6 \%$ & $66.9 \%$ \\
\hline & $7 \mathrm{~N}$ & $2.2 \%$ & $0.0 \%$ & $31.3 \%$ & $65.8 \%$ \\
\hline & $10 \mathrm{~N}$ & $28.8 \%$ & $34.6 \%$ & $16.5 \%$ & $43.6 \%$ \\
\hline
\end{tabular}

Figure 4 presents a schematic illustration of the wear mechanisms prevalent during sliding wear of the composites reinforced by CNFs. The continuous transfer film formed during 
the running-in stage is mainly composed of worn matrix material and can effectively reduce the 'direct contact' of the composite with asperities of the hard metallic counterface (Bahadur, 2000; Myshkin, Petrokovets \& Kovalev, 2006). During the sliding process, the CNFs reinforcement may carry most of the contact load and wear against the counterpart. Furthermore, thermalmechanical failure of the material in this contact region may occur, due to the high friction and local heating (Chang \& Friedrich, 2010). In this case, the polymeric matrix in the interfacial region around CNFs solid phase suffers higher stress and temperature. As a result, the CNFs will be removed more easily which is associated with a progressive increase in the wear rate of the composites. Therefore, detached CNFs solid phase can fill the gap between the asperities and reduce the roughness of the counterpart and consequently, decrease the COF and volume loss.

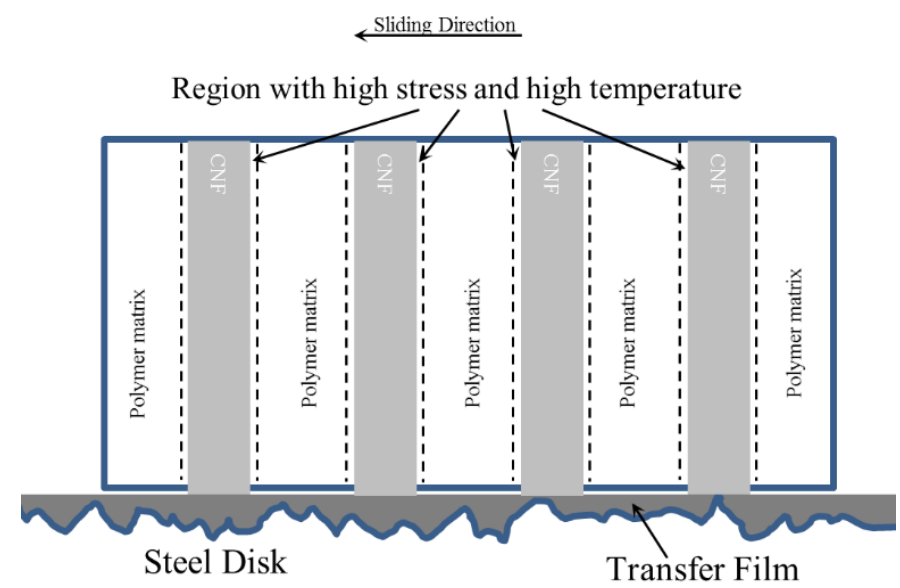

Figure 4 Schematic illustration of the failure mechanism for the sliding wear of CNFs/bio-epoxy nanocomposites

To understand the role of nano-cellulose fibers on the wear mechanism, two composite samples with different CNFs contents and a neat bio-epoxy sample were chosen for comparison. Their worn surfaces were further investigated by using stereo-macrograph and SEM. The texture of worn surfaces clearly depicts the composition-dependent wear behavior. For comparison purpose, all the selected samples were subjected to the same normal loads and sliding speed. The surface damage on the worn surface is decreased by adding nano-cellulose to the bio-epoxy matrix. This reduced the wear volume loss and hence the nanocomposites showed improved wear resistance when compared to the neat bio-epoxy materials as there were no fibers to support the matrix of neat bio-epoxy. Hence, the important reason for better wear resistance of the composites is the load bearing ability of CNFs in the matrix. Moreover, by increasing the content of CNF, more fibers can shoulder the load which tends to decrease the wear rate at higher 
volume fraction of CNFs. The SEM image of the worn surface of neat bio-epoxy showed more debris and fine cutting chips similar to those produced during machining. It means that the wear mechanism of neat bio-epoxy is abrasive. The detached debris act as third body abrasive. These debris can further increase the depth of the grooves by ploughing action and the material is continually displaced sideways to form ridges adjacent to the developing groove by plastic deformation. In addition, the debris can cut the surface similar to micromachining and all the material displaced by the debris is removed as a chip. Consequently, the volume loss increases in neat bio-epoxy as confirmed by the experimental results presented.

On the other hand, a minimal amount of debris is seen on the surface of $0.9 \% \mathrm{CNF} / \mathrm{bio}-$ epoxy composites and no debris are found on the surface of $1.4 \% \mathrm{CNFs} /$ bio-epoxy composites. Therefore, the composites exhibited lower wear rates. The SEM image of the worn surfaces exhibit that the dominant wear mechanism for the composites is adhesion due to plastic deformation and in some regions transfer layer is seen on the composite surfaces. A distinguishing feature of this wear process is the back transfer of material from one surface to another where iron from steel is transferred to the polymer surface (Xian, Walter \& Haupert, 2006). A similar observation is reported in the literature where a soft aluminum materials slide against a hard steel counter material and iron from the steel counter material is transferred to the soft aluminum sample surface (Menezes \& Kailas, 2008, 2009). This phenomena occurs due to the localized bonding between the contacting solid surfaces (Myshkin, Petrokovets \& Kovalev, 2006). Because of the presence of some debris on the worn surface of $0.9 \% \mathrm{CNFs} / \mathrm{bio}$-epoxy composites, the wear mechanism for this composite is a combination of abrasion and adhesion with latter being dominant. On the other hand, the wear mechanism of $1.4 \% \mathrm{CNFs} /$ bio-epoxy composites is completely adhesive in nature.

By investigating the worn surfaces, it is obvious that the surfaces of the composites are smoother than that of the neat bio-epoxy. The smooth surface is indicative of the lower wear rates being prevalent for the composites. The 3D images of the worn surfaces (Figure 5) confirm that the surface of composites are less coarse with the roughness parameter, the maximum heights of the profile $\left(R_{\mathrm{t}}\right)$, being $37.3,22.9$, and $21.6 \mu \mathrm{m}$ for the neat bio-epoxy, $0.9 \%$ CNFs/bioepoxy, and $1.4 \% \mathrm{CNFs} /$ bio-epoxy, respectively. Generally, once the nano-cellulose fibers were incorporated, the worn surfaces appear much smoother even at severe wear conditions (at the 
highest normal load and sliding speed), in comparison with the neat bio-epoxy without nanofibers.
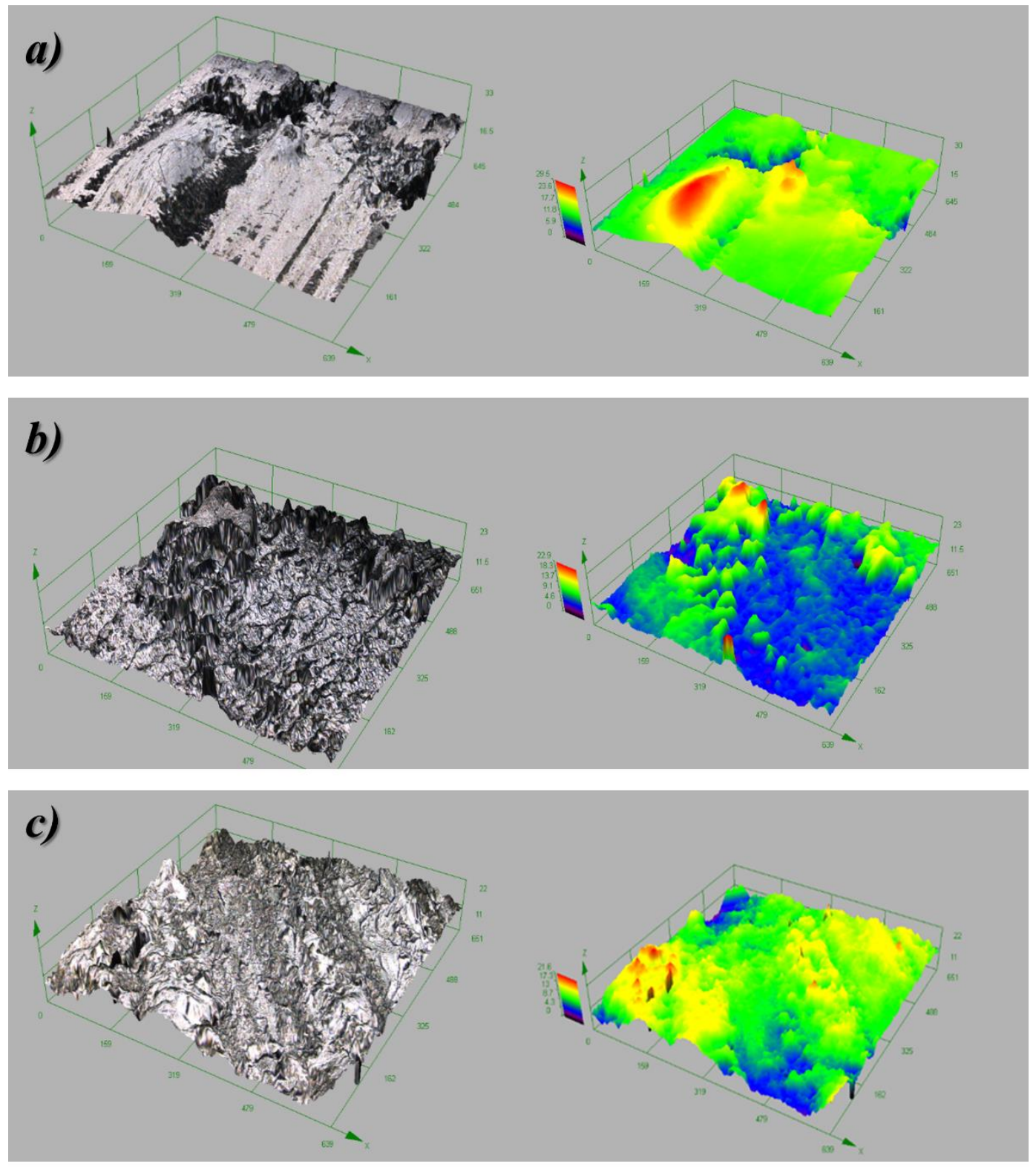

Figure 53 Durface topography of a) neat epoxy, b) bio-epoxy reinforced by 0.9 vol.\% nano-cellulose, and c) bioepoxy reinforced by 1.4 vol.\% nano-cellulose at $7 \mathrm{~N}$ normal load and $0.15 \mathrm{~m} / \mathrm{s}$

\subsubsection{Effect of normal load}

The effect of normal load on COF of neat bio-epoxy and nano-cellulose/bio-epoxy composites is shown in Figure 6(a), (b) and (c). It can be seen that the COF increases with 
increasing normal load for neat bio-epoxy while the COF decreases with increasing normal load for nano-cellulose/bio-epoxy nanocomposites. The effect of normal load on wear volume loss of neat bio-epoxy and nano-cellulose/bio-epoxy is shown in Figure 6(d), (e) and (f). Increasing the normal load tends to increase the wear volume loss due to high deformation and more detritions on the surface of composites. As stated earlier, more CNF reinforcements are exposed to the contact surface at higher normal load. Hence, a transfer layer forms at the contact surface which reduces direct surface contact. Consequently, the coefficient of friction is decreased.
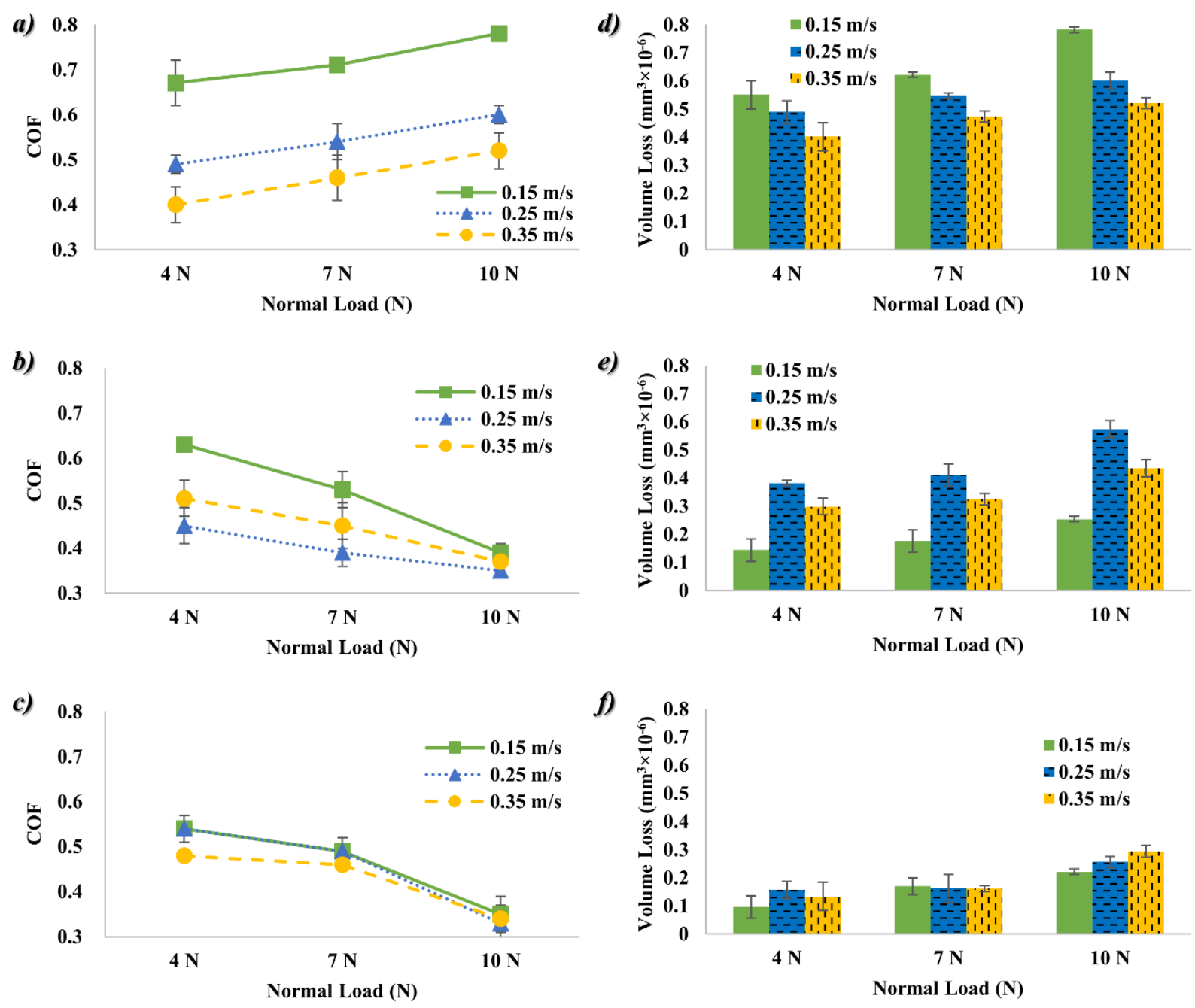

Figure 6 Effect of normal load on COF of a) neat bio-epoxy, b) 0.9 vol.\% nano-cellulose/bio-epoxy, and c) 1.4 vol.\% nano-cellulose/bio-epoxy at different sliding speeds and effect of normal load on wear volume of d) neat bio-epoxy, e) 0.9 vol.\% nano-cellulose/bio-epoxy, and f) 1.4 vol.\% nano-cellulose/bio-epoxy at different sliding speeds

Figure 7 (a) and (b) exhibits the worn surface of bio-epoxy nanocomposites reinforced by 1.4 vol. \% nano-cellulose at a constant sliding speed $0.15 \mathrm{~m} / \mathrm{s}$ for low and high normal load 
conditions. It is obvious that there are cracks on the surface of composites tested with higher load while no crack can be found on the surface of composites with low loads. Consequently, the wear rate is greater at the higher applied load due to the deterioration of materials in the presence of cracks. In addition, Figure 7 (c) and (d) shows that the bonding between nano-cellulose and bio-epoxy was broken at higher normal load, therefore, CNFs were not able to carry the load and hence the load bearing ability of CNFs decreased and it tended to have higher wear rates at higher normal loads.
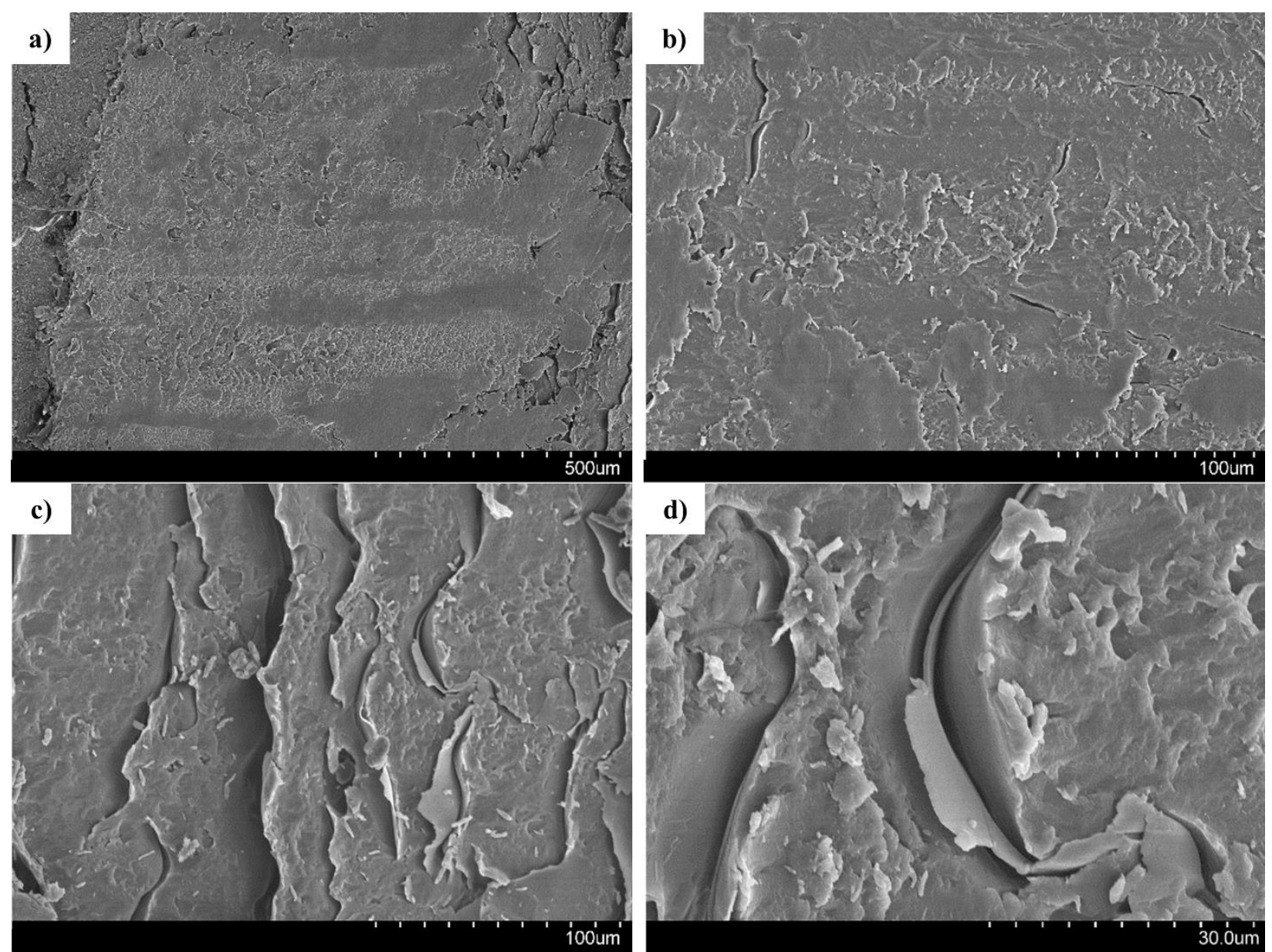

Figure 7 Worn surface of bio-epoxy nanocomposites reinforced by 1.4 vol.\% nano-cellulose at a) $4 \mathrm{~N}$ and b) $10 \mathrm{~N}$ applied load at $0.15 \mathrm{~m} / \mathrm{s}$ and worn surface of bio-epoxy nanocomposites reinforced by 1.4 vol.\% nano-cellulose at $10 \mathrm{~N}$ applied load and $0.15 \mathrm{~m} / \mathrm{s}$ sliding speed at (c) $500 \mathrm{X}$ and (d) $1800 \mathrm{X}$ magnifications.

\subsubsection{Effect of sliding speed}

Figure 8 (a), (b) and (c) shows the variation of COF with sliding speed for the neat bioepoxy and the nano-cellulose/bio-epoxy nanocomposites at different normal loads. The neat bioepoxy shows a reduction in COF with increasing sliding speed. For the 0.9 vol.\% nano- 
cellulose/bio-epoxy composite, the COF decreased with increasing sliding speed up to $0.25 \mathrm{~m} / \mathrm{s}$ and then it further increased with the increasing sliding speed till $0.35 \mathrm{~m} / \mathrm{s}$. These variations are significantly less at the $10 \mathrm{~N}$ normal load. Despite having an increasing COF with the increasing speed, the COF of nanocomposite is less than that of the neat bio-epoxy. The 1.4 vol.\% nanocellulose/bio-epoxy composite exhibits different tribological behavior at low, medium, and high normal loads. The COF increases and then slightly decreases for the $4 \mathrm{~N}$ normal load. For the $7 \mathrm{~N}$ normal load, the COF does not change much when the speed changes from 0.15 to $0.25 \mathrm{~m} / \mathrm{s}$. However, it slightly decreases for $0.35 \mathrm{~m} / \mathrm{s}$. On the other hand, at the higher normal load of $10 \mathrm{~N}$, the $\mathrm{COF}$ decreases and then increases with the increasing sliding speed. The variation of wear volume with the sliding speed for the neat bio-epoxy and the nano-cellulose/bio-epoxy nanocomposites at different normal loads is depicted in Figure 8(d), (e) and (f). When the sliding speed increases, the wear volume of the neat bio-epoxy decreases. For the 0.9 vol.\% nanocellulose/bio-epoxy, the wear volume increases with the increasing sliding speed up to $0.25 \mathrm{~m} / \mathrm{s}$ and then it decreases at the sliding speed of $0.35 \mathrm{~m} / \mathrm{s}$ where the wear of the nanocomposite is less than that of the neat bio-epoxy. The wear volume for the $1.4 \mathrm{vol} . \%$ nano-cellulose/bio-epoxy increases with the increasing sliding velocity, but this variation is less significant when compared with that of the neat bio-epoxy and 0.9 vol.\% nano-cellulose/bio-epoxy composites. 

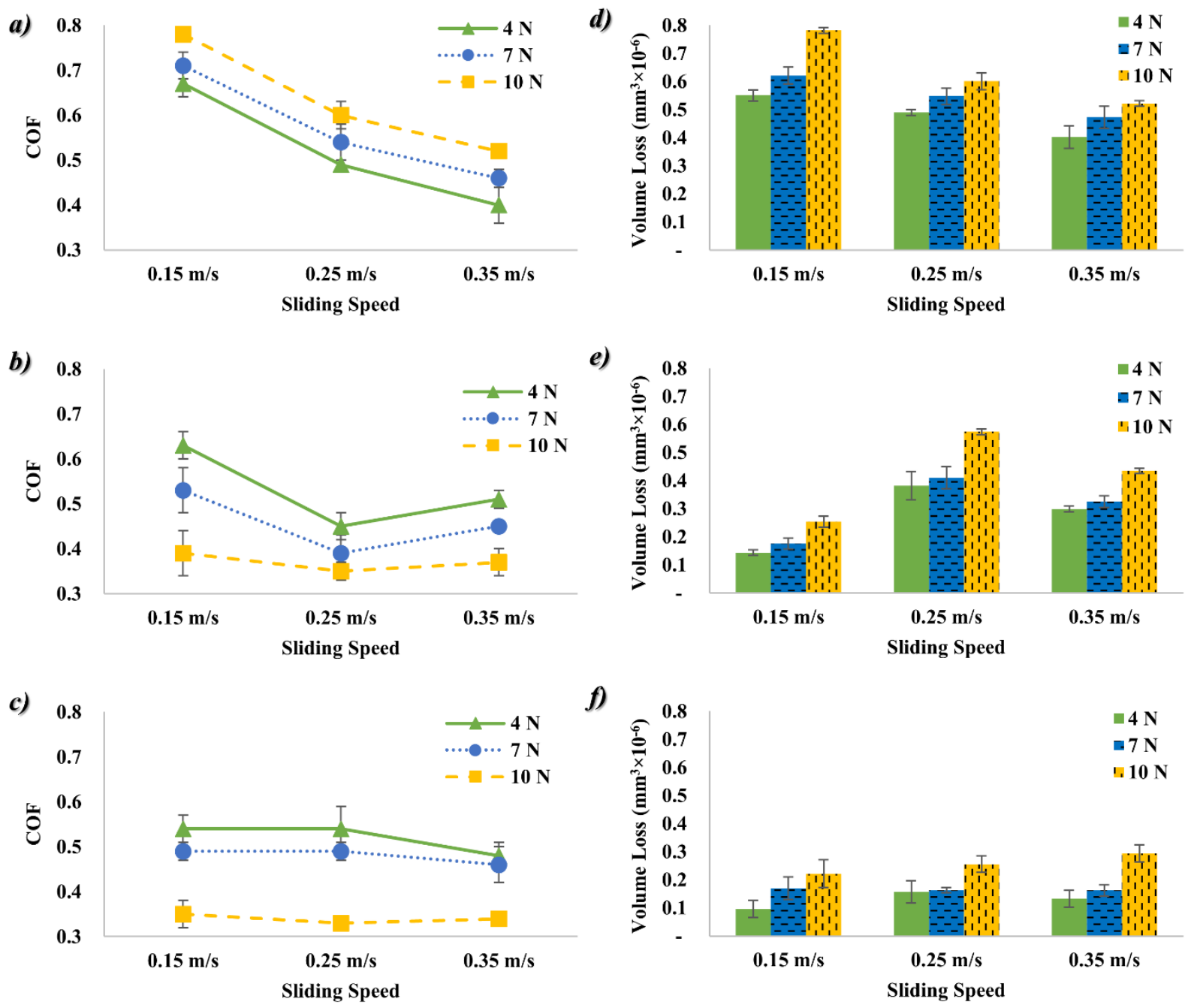

Figure 8 Effect of sliding speed on COF of nano-cellulose/ bio-epoxy nanocomposites for a) neat bio-epoxy, b) 0.9 vol.\% nano-cellulose/bio-epoxy, and c) 1.4 vol.\% nano-cellulose/bio-epoxy at different normal loads effect of sliding speed on wear volume of nano-cellulose/ bio-epoxy nanocomposites for d) neat bio-epoxy, e) 0.9 vol.\% nano-cellulose/bio-epoxy, and f) 1.4 vol.\% nano-cellulose/bio-epoxy at different normal load.

\section{Summery and Conclusions}

In this study, a bio- based epoxy composite reinforced with freeze dried, silylated and non-silylated CNF preforms was prepared using an improvised LCM process where the resin was imbibed inside the preform through vacuum suction. The isothermal and dynamic DSC tests were conducted to investigate the cure kinetics of bio-epoxy in the presence of CNF preforms. The investigations revealed that the reaction between the siloxane groups and the bio-epoxy rings showed catalytic effects on the curing of bio-epoxy in the presence of CNFs which improved the mechanical properties of the silylated CNF composites compared to the nonsilylated samples. In addition, the kinetic behavior of the treated and non-treated CNF 
composites was studied and a relation was derived for the conversion as a function of time. The mechanical testing results also correlated with the results obtained by DSC where the highest ultimate strength and elastic moduli obtained for the silylated CNF coupons. The moderate global mechanical properties of the manufactured CNF composites could be explained as a result of low mechanical properties of the used bio-based epoxy and low fiber volume fractions due to the highly porous structure of CNF. Tribological behavior of the silylated CNFs composites showed lower COFs and wear volumes than the neat bio-epoxy due to the formation of a transfer film on the mating surfaces, which led to a decrease in the 'direct contact' of the composite with the asperities of the hard metallic counterface. At higher loads, the COF is decreased for the composites due to the higher wear rates and more exposed CNF fibers on the surfaces. No consistent correlation between the sliding speed and COF/volume loss was observed.

\section{Acknowledgement}

The authors would like to thank and acknowledge the efforts of Professor Lih-Sheng Turng and Mr. Thomas K Ellingham of University of Wisconsin-Madison and Dr. Ronald C Sabo of the USDA Forest Products Laboratory at Madison for preparing CNF preforms and creating SEM micrographs. The authors would also thank and acknowledge the efforts of Professor Rani El-Hajjar and Mr. Issam I Qamhia of the Experimental Mechanics and Composites Laboratories at the University of Wisconsin-Milwaukee (UWM) for performing mechanical testing. The funding in the form of RGI grant from the graduate school of UWM and the intercampus grant from the UW System is gratefully acknowledged.

\section{References}

Alamri, H., \& Low, I. M. (2012a). Mechanical properties and water absorption behaviour of recycled cellulose fibre reinforced epoxy composites. Polymer testing, 31(5), 620-628.

Alamri, H., \& Low, I. M. (2012b). Microstructural, mechanical, and thermal characteristics of recycled cellulose fiber-halloysite-epoxy hybrid nanocomposites. Polymer Composites, 33(4), 589-600.

Alawar, A., Hamed, A. M., \& Al-Kaabi, K. (2009). Characterization of treated date palm tree fiber as composite reinforcement. Composites Part B: Engineering, 40(7), 601-606.

Bahadur, S. (2000). The development of transfer layers and their role in polymer tribology. Wear, 245(1), 92-99. 
Balali, M. H., Nouri, N., \& Pakdamanian, E. (2013). Application of the Minimax Control Chartfor multivariate manufacturing process.

Barari, B., Ellingham, T., Qamhia, I. I., Pillai, K. M., El-Hajjar, R., Turng, L.-S., \& Sabo, R. (2015). Mechanical characterization of scalable cellulose nano-fiber based composites made using liquid composite molding process. Composites Part B: Engineering.

Barari, B., \& Pillai, K. (2014). Calibration of one-dimensional flow setup used for estimating fabric permeability using three different reference media. Polymer Composites.

Barari, B., \& Pillai, K. M. (2015). Search for a 'Green'Composite Material: An Attempt to Fabricate Cellulose Nano-Fiber Composites using Liquid Composite Molding. Journal of the Indian Institute of Science, 95(3), 313-320.

Brosius, D. (2006). Natural fiber composites slowly take root. Composites Technology, 32-37.

Chand, N., \& Dwivedi, U. (2006). Effect of coupling agent on abrasive wear behaviour of chopped jute fibre-reinforced polypropylene composites. Wear, 261(10), 1057-1063.

Chand, N., \& Dwivedi, U. (2007). High stress abrasive wear study on bamboo. Journal of materials processing technology, 183(2), 155-159.

Chang, L., \& Friedrich, K. (2010). Enhancement effect of nanoparticles on the sliding wear of short fiber-reinforced polymer composites: a critical discussion of wear mechanisms. Tribology International, 43(12), 2355-2364.

Cheung, H.-y., Ho, M.-p., Lau, K.-t., Cardona, F., \& Hui, D. (2009). Natural fibre-reinforced composites for bioengineering and environmental engineering applications. Composites Part B: Engineering, 40(7), 655-663.

Chin, C., \& Yousif, B. (2009). Potential of kenaf fibres as reinforcement for tribological applications. Wear, 267(9), 1550-1557.

Haque, M. M., Hasan, M., Islam, M. S., \& Ali, M. E. (2009). Physico-mechanical properties of chemically treated palm and coir fiber reinforced polypropylene composites. Bioresource technology, 100(20), 4903-4906.

Henriksson, M., \& Berglund, L. A. (2007). Structure and properties of cellulose nanocomposite films containing melamine formaldehyde. Journal of Applied Polymer Science, 106(4), 28172824.

Henriksson, M., Berglund, L. A., Isaksson, P., Lindström, T., \& Nishino, T. (2008). Cellulose nanopaper structures of high toughness. Biomacromolecules, 9(6), 1579-1585.

Hepworth, D., Vincent, J., Jeronimidis, G., \& Bruce, D. (2000). The penetration of epoxy resin into plant fibre cell walls increases the stiffness of plant fibre composites. Composites Part A: Applied Science and Manufacturing, 31(6), 599-601.

Hüsing, N., \& Schubert, U. (1998). Aerogels - airy materials: chemistry, structure, and properties. Angewandte Chemie International Edition, 37(1-2), 22-45.

Innerlohinger, J., Weber, H. K., \& Kraft, G. (2006). Aerocellulose: Aerogels and Aerogel-like Materials made from Cellulose. Macromolecular Symposia (Vol. 244, pp. 126-135): Wiley Online Library.

Jonoobi, M., Harun, J., Mathew, A. P., \& Oksman, K. (2010). Mechanical properties of cellulose nanofiber (CNF) reinforced polylactic acid (PLA) prepared by twin screw extrusion. Composites Science and Technology, 70(12), 1742-1747.

Kim, S.-J., Moon, J.-B., Kim, G.-H., \& Ha, C.-S. (2008). Mechanical properties of polypropylene/natural fiber composites: comparison of wood fiber and cotton fiber. Polymer testing, 27(7), 801-806. 
Ku, H., Wang, H., Pattarachaiyakoop, N., \& Trada, M. (2011). A review on the tensile properties of natural fiber reinforced polymer composites. Composites Part B: Engineering, 42(4), 856873.

Lee, S.-Y., Chun, S.-J., Kang, I.-A., \& Park, J.-Y. (2009). Preparation of cellulose nanofibrils by high-pressure homogenizer and cellulose-based composite films. Journal of Industrial and Engineering Chemistry, 15(1), 50-55.

Leyland, A., \& Matthews, A. (2000). On the significance of the H/E ratio in wear control: a nanocomposite coating approach to optimised tribological behaviour. Wear, 246(1), 1-11.

Low, I. M., Somers, J., Kho, H., Davies, I., \& Latella, B. (2009). Fabrication and properties of recycled cellulose fibre-reinforced epoxy composites. Composite Interfaces, 16(7-9), 659-669.

Masoodi, R., El-Hajjar, R., Pillai, K., \& Sabo, R. (2012). Mechanical characterization of cellulose nanofiber and bio-based epoxy composite. Materials \& Design, 36, 570-576.

Menezes, P. L., \& Kailas, S. V. (2008). On the effect of surface texture on friction and transfer layer formation - a study using Al and steel pair. Wear, 265(11), 1655-1669.

Menezes, P. L., \& Kailas, S. V. (2009). Influence of surface texture and roughness parameters on friction and transfer layer formation during sliding of aluminium pin on steel plate. Wear, 267(9), 1534-1549.

Menezes, P. L., Nosonovsky, M., Kailas, S. V., \& Lovell, M. R. (2013). Friction and wear. Tribology for Scientists and Engineers (pp. 43-91): Springer.

Myshkin, N., Petrokovets, M., \& Kovalev, A. (2006). Tribology of polymers: adhesion, friction, wear, and mass-transfer. Tribology International, 38(11), 910-921.

Nirmal, U., Hashim, J., \& Low, K. (2012). Adhesive wear and frictional performance of bamboo fibres reinforced epoxy composite. Tribology International, 47, 122-133.

Omrani, E., Menezes, P. L., \& Rohatgi, P. K. (2015). State of the art on tribological behavior of polymer matrix composites reinforced with natural fibers in the green materials world. Engineering Science and Technology, an International Journal.

Plackett, D., Andersen, T. L., Pedersen, W. B., \& Nielsen, L. (2003). Biodegradable composites based on L-polylactide and jute fibres. Composites Science and Technology, 63(9), 1287-1296.

Qamhia, I. I., Shams, S. S., \& El-Hajjar, R. F. (2015). Quasi-Isotropic Triaxially Braided Cellulose-Reinforced Composites. Mechanics of Advanced Materials and Structures, 22(12), 988-995.

Saha, P., Manna, S., Chowdhury, S. R., Sen, R., Roy, D., \& Adhikari, B. (2010). Enhancement of tensile strength of lignocellulosic jute fibers by alkali-steam treatment. Bioresource technology, 101(9), 3182-3187.

Saito, T., Hirota, M., Tamura, N., Kimura, S., Fukuzumi, H., Heux, L., \& Isogai, A. (2009). Individualization of nano-sized plant cellulose fibrils by direct surface carboxylation using TEMPO catalyst under neutral conditions. Biomacromolecules, 10(7), 1992-1996.

Shalwan, A., \& Yousif, B. (2013). In State of Art: Mechanical and tribological behaviour of polymeric composites based on natural fibres. Materials \& Design, 48, 14-24.

Shibata, S., Cao, Y., \& Fukumoto, I. (2005). Press forming of short natural fiber-reinforced biodegradable resin: Effects of fiber volume and length on flexural properties. Polymer testing, 24(8), 1005-1011.

Tan, C., Fung, B., Newman, J., \& Vu, C. (2001). Organic aerogels with very high impact strength. Advanced materials, 13(9), 644-646. 
Teixeira, E. d. M., Pasquini, D., Curvelo, A. A., Corradini, E., Belgacem, M. N., \& Dufresne, A. (2009). Cassava bagasse cellulose nanofibrils reinforced thermoplastic cassava starch. Carbohydrate polymers, 78(3), 422-431.

Tjong, S., \& Tam, K. (2006). Mechanical and thermal expansion behavior of hipped aluminumTiB 2 composites. Materials Chemistry and physics, 97(1), 91-97.

Venkateshwaran, N., Elayaperumal, A., \& Sathiya, G. (2012). Prediction of tensile properties of hybrid-natural fiber composites. Composites Part B: Engineering, 43(2), 793-796.

Virk, A. S., Hall, W., \& Summerscales, J. (2010). Failure strain as the key design criterion for fracture of natural fibre composites. Composites Science and Technology, 70(6), 995-999.

Wambua, P., Ivens, J., \& Verpoest, I. (2003). Natural fibres: can they replace glass in fibre reinforced plastics? Composites Science and Technology, 63(9), 1259-1264.

Xian, G., Walter, R., \& Haupert, F. (2006). Friction and wear of epoxy/TiO 2 nanocomposites: Influence of additional short carbon fibers, Aramid and PTFE particles. Composites Science and Technology, 66(16), 3199-3209.

Yousif, B., \& El-Tayeb, N. (2008). Adhesive wear performance of T-OPRP and UT-OPRP composites. Tribology letters, 32(3), 199-208.

Yousif, B., Lau, S. T., \& McWilliam, S. (2010). Polyester composite based on betelnut fibre for tribological applications. Tribology International, 43(1), 503-511. 